\title{
Legal concerns after a patient suicide
}

\author{
Nina E. Ross, MD, Gary Ciuffetelli, MD, and John S. Rozel, MD
}

Dr. Ross is a Forensic Psychiatry Fellow, Case Western Reserve University/University Hospitals Cleveland Medical Center, Cleveland, Ohio. Dr. Ciuffetelli is a Forensic Psychiatrist in Sacramento, California. Dr. Rozel is Associate Professor of Psychiatry, Department of Psychiatry University of Pittsburgh Medical Center, Pittsburgh, Pennsylvania.

Disclosures

The authors report no financial relationships with any companies whose products are mentioned in this article, or with manufacturers of competing products.

doi: 10.12788/cp.0051

\section{$f$}

Discuss this article at www.facebook.com/ MDedgePsychiatry 6
M ost psychiatrists will care for at least one patient who dies by suicide. Many clinicians consider this to be one of the most stressful and formative events of their careers, prompting strong emotions, logistical questions, and legal concerns. Because the aftermath of a patient suicide can be difficult, we offer guidance on how to cope with such events, and specifically how to address the legal concerns.

Attend to self-care. "At a cardiac arrest, the first procedure is to take your own pulse." This advice, from Samuel Shem's The House of God, highlights the importance of selfawareness during highly stressful events. ${ }^{1}$ When facing the aftermath of a patient suicide, be sure to attend to your own needs, such as eating, staying hydrated, and getting enough sleep. Identify and reach out to your support systems, such as friends and family. Your colleagues can be a source of support, both formally or informally. Reaching out to other psychiatrists, who likely have their own experience with patient suicide, can help process the event. A support group consisting of other psychiatrists also may be beneficial. Finally, avoid blaming yourself. Although you might perceive your patient's suicide as a personal failing, suicide is notoriously difficult to predict and an unfortunate reality of working in this specialty.

Report the event. Follow your institution's guidelines for reporting adverse events. You may be required to inform your supervisor, the risk management department, legal services, your malpractice provider, and/or the police. Your risk manage- ment department and malpractice provider may have their own regulations and recommendations.

Review the case. Institutions often have established processes for reviewing adverse events and, if applicable, suggesting constructive feedback or general quality improvements. A review process may provide an opportunity to look for potential negligence that could be an issue if there is a malpractice suit. Ideally, such processes are constructive and a time for reflection, rather than punitive or blaming. Trainees may find their supervisors' presence and guidance to be particularly helpful during this review process.

Assess malpractice risk. Although psychiatrists have a relatively low risk of being sued for malpractice, many lawsuits against psychiatrists occur after a completed patient suicide. ${ }^{2}$ In a successful malpractice suit, the plaintiff needs to establish all 4 "Ds" of medical malpractice:

1) Duty, or an established physicianpatient relationship

2) Damages from an adverse event

3) Dereliction of duty (negligence)

Every issue of CuRrent Psychiatry has its 'Pearls'

Yours could be found here.

Read the 'Pearls' guidelines for manuscript submission at MDedge.com/ CurrentPsychiatry/page/pearls. Then, share with your peers a 'Pearl' of wisdom from your practice. 
4) Direct causality between the deviation and the damages.

In the event of a patient suicide, both a doctor-patient relationship (duty) and an adverse outcome (damages) exist. ${ }^{3}$ Establishing dereliction of duty and direct causality rests on the plaintiff to prove. Good documentation can serve as evidence against accusations of negligence. ${ }^{3}$

Typically, a patient's medical record will be used as evidence in a malpractice suit. After a suicide, do not alter this record, such as by editing your past assessments of the patient. If an addendum must be made, such as to document a conversation with suicide survivors (family and friends of the deceased), be sure to label it as such with the current date. An addendum should contain only facts; avoid adding information that attempts to explain your patient's suicide, justifying or apologizing for past treatment decisions, or otherwise editorializing.

\section{Consider reaching out to suicide survi-}

vors. The Health Insurance Portability and Accountability Act permits clinicians to use their best judgment when identifying individuals to contact and deciding what information to share after a patient's death. ${ }^{4}$ Some states and practice settings have stricter confidentiality laws. Consider seeking legal counsel before interacting with suicide survivors.

Suicide survivors may experience feelings such as guilt, shame, and anger, and these feelings may lead suicide survivors to file a malpractice suit. ${ }^{3}$ Speaking with suicide survivors can help to address these feelings and potentially decrease the likelihood of them pursuing a malpractice suit.
In addition, suicide survivors are at high risk for developing mental health issues, including suicidality. Contacting them can be an opportunity to encourage them to seek mental health treatment. It is important to clarify that any recommendations you provide in such situations do not constitute a doctor-patient relationship.

Should you offer an apology? Consider seeking legal counsel if you wish to apologize. Some states have "apology laws" that render a clinician's apologetic statements inadmissible if a malpractice suit should occur. $^{5}$ These laws might include empathic statements ("I'm sorry for your loss") or disclosures of error ("I'm sorry for causing your loss"). ${ }^{5}$ It is unclear whether these laws affect the likelihood and/or outcome of malpractice suits. ${ }^{5}$

Focus on empathy. Experiencing a patient suicide can be one of the most challenging events in a psychiatrist's career. Empathy is crucial, both towards the suicide survivors and to oneself.

\section{References}

1. Shem S. The House of God. New York, NY: Berkley Books; 2010.

2. Schaffer $A C$, Jena $A B$, Seabury $S A$, et al. Rates and characteristics of paid malpractice claims among US physicians by specialty, 1992-2014. JAMA Intern Med. 2017;177(5):710-719.

3. Gutheil TG, Appelbaum PS. Clinical handbook of psychiatry and the law, 3rd ed. Baltimore, MD: Lippincott Williams \& Wilkins; 2000.

4. Office of Civil Rights. How can a covered entity determine if a person is a family member prior to an individual's death. US Department of Health and Human Services. https:// www.hhs.gov/hipaa/for-professionals/faq/1505/ how-can-a-covered-entity-determine-whether-a-person -is-a-family-member/index.html. Accessed September 9, 2020.

5. McMichael BJ, Van Horn RL, Viscusi WK. "Sorry" is never enough: how state apology laws fail to reduce medical malpractice liability risk. Stanford Law Rev. 2019;71(2): 341-409.

\section{Some states' 'apology laws' can render a clinician's apologetic statements inadmissible in a malpractice suit}

